\title{
Plantas medicinais no combate ao biofilme dental: revisão da literatura
}

Medicinal plants in combating dental biofilm: literature review

Plantas medicinales en el combate al biofilm dental: revisión de literatura

André Paulo Gomes SIMÕES

Abrahão Alves de OLIVEIRA FILHO

Unidade Acadêmica de Ciências Biológicas, Centro de Saúde e Tecnologia Rural, Universidade Federal de Campina Grande (UFCG) 58428-830 Campina Grande - PB, Brasil

\section{Resumo}

O crescimento mundial da fitoterapia como método de prevenção e combate as patologias, acabou estimulando a avaliação das atividades no controle de biofilme dental a partir de extratos de plantas. Objetivou-se realizar uma breve revisão da literatura sobre as principais plantas medicinais que são utilizadas no combate ao biofilme bucal pelo mundo. Trata-se de uma análise de dados secundários, por meio de uma revisão da literatura do tipo narrativa com base nos bancos de dados: Biblioteca Virtual em Saúde (BVS), Scientific Eletronic Library Online (Scielo), National Center for Biotechnology Information (Pubmed), Literatura Latino-americana e do Caribe em Ciências da Saúde (LILACS) e Medical Literature Analysis and Retrieval System Online (Medline). Foram utilizados os descritores biofilme dental, fitoterapia, plantas medicinais, além dos termos correspondestes em inglês e espanhol. Utilizados como critérios de inclusão trabalhos publicados em português, inglês e espanhol no período de 2009 a 2019 no formato de artigo, tese e dissertação, tendo a busca dos dados ocorrida de julho a agosto de 2018. Dentre as famílias mais utilizadas no combate ao biofilme dental, destacaram-se as famílias Asteraceae e Anacardiaceae, sendo as que mais apresentaram estudos sobre esse tema. Diante da revisão realizada pode-se concluir que as plantas medicinais têm apresentado resultados bastante significativos no combate ao biofilme dental, seja por suas propriedades antimicrobianas ou pelo seu potencial antiaderente frente as bactérias formadoras do biofilme dental. Sugere-se a realização de mais estudos e ensaios clínicos para métodos convencionais no combate ao biofilme dental e consequentemente da cárie dentária.

Descritores: Plantas Medicinais; Fitoterapia; Biofilmes; Placa Dentária.

\section{Abstract}

The worldwide growth of phytotherapy as a method of prevention and control of pathologies, ended up stimulating the evaluation of activities in the control of dental biofilm from plant extracts. The objective of this study was to carry out a brief review of the literature on the main medicinal plants used in the fight against oral biofilms in the world. It is an analysis of secondary data, through a literature review of the narrative type based on the databases: Virtual Health Library (VHL), Scientific Electronic Library Online (Scielo), National Center for Biotechnology Information ), Latin American and Caribbean Literature in Health Sciences (LILACS) and Medical Literature Analysis and Retrieval System Online (Medline). The descriptors were biofilm dental, phytotherapy, medicinal plants, in addition to the corresponding terms in English and Spanish. The inclusion criteria were papers published in Portuguese, English and Spanish in the period from 2009 to 2019 in the format of article, thesis and dissertation, with data search from July to August 2018. Among the families most used in the fight against biofilm dental, the Asteraceae and Anacardiaceae families were the most studied, being the ones that presented more studies on this subject. In view of the review carried out, it can be concluded that medicinal plants have presented quite significant results in the fight against dental biofilm, either because of its antimicrobial properties or because of its non-adherent potential against the bacteria forming the dental biofilm. Further studies and clinical trials are suggested for conventional methods in the fight against dental biofilm and consequently of dental caries.

Descriptors: Plants, Medicinal; Phytotherapy; Biofilms; Dental Plaque.

\section{Resumen}

El crecimiento mundial de la fitoterapia como método de prevención y combate a las patologías, acabó estimulando la evaluación de las actividades en el control de biopelícula dental a partir de extractos de plantas. Se objetivó realizar una breve revisión de la literatura sobre las principales plantas medicinales que son utilizadas en el combate al biofilm bucal por el mundo. Se trata de un análisis de datos secundarios, a través de una revisión de la literatura del tipo narrativa basada en los bancos de datos: Biblioteca Virtual en Salud (BVS), Scientific Electronic Library Online (Scielo), National Center for Biotechnology Information (Pubmed), Literatura Latinoamericana y del Caribe en Ciencias de la Salud (LILACS) y Medical Literature Analysis and Retrieval System Online (Medline). Se utilizaron los descriptores biofilm dental, fitoterapia, plantas medicinales, además de los términos correspondientes en inglés y español. Utilizar como criterios de inclusión para los trabajos publicados en portugués, Inglés y Español en el periodo 2009-2019 en formato artículo, tesis y tesis, y la búsqueda de los datos se llevó a cabo entre julio y agosto de 2018. Entre las familias más utilizadas para combatir el biofilm dental, se destacaron las familias Asteraceae y Anacardiaceae, siendo las que más presentaron estudios sobre ese tema. Ante la revisión realizada se puede concluir que las plantas medicinales han presentado resultados bastante significativos en el combate al biofilm dental, ya sea por sus propiedades antimicrobianas o por su potencial antiadherente frente a las bacterias formadoras del biofilm dental. Se sugiere la realización de más estudios y ensayos clínicos para métodos convencionales en el combate al biopelícula dental y consecuentemente de la caries dental.

Descriptores: Plantas Medicinales; Fitoterapia; Placa Dental.

INTRODUÇÃO

A fitoterapia é o saber que investiga o uso de plantas ou parte delas no tratamento de patologias que atingem os humanos ${ }^{1}$. O uso de plantas medicinais como terapia teve início na origem da medicina e tem crescido como interesse do povo, da ciência e das organizações ${ }^{2}$. Ao longo dos anos, os produtos de origem vegetal formaram bases no combate a diversas doenças, seja devido ao conhecimento das plantas passado de geração a geração, seja pelo uso de algumas espécies vegetais como fonte de partículas ativas ${ }^{3}$.

O Ministério da Saúde relata a fitoterapia como sendo um método de tratamento caracterizado pelo uso de plantas medicinais em suas diferentes formas de utilização, com a ausência de substâncias ativas isoladas, mesmo que de origem vegetal. No Brasil, este tema tem sido acercado na área da saúde 
coletiva, seguindo as orientações da Organização Mundial da Saúde (OMS) para o uso da medicina alternativa no Sistema único de saúde (SUS), em conjunto às técnicas da medicina ocidental moderna. A fitoterapia integra, desta forma, uma das práticas propostas na Política Nacional de Práticas Integrativas e Complementares (PNPIC) proposta em $2006^{4}$.

Outro documento importante é a Relação Nacional de Plantas Medicinais de interesse ao SUS (Renisus), criada em 2009, a qual aborda 71 plantas medicinais que devem ser investigadas e introduzidas nos serviços de saúde públicos brasileiros ${ }^{5}$. Dentre essas, várias espécies são indicadas para o combate ao biofilme dental, resultando em uma valorização das práticas baseadas em plantas medicinais, que são disseminadas entre as gerações.

O vocábulo "biofilme" é utilizado para se referir a comunidades de microrganismos aderidos a uma superfície, de forma organizada em uma estrutura de três dimensões, tendo como base o material extracelular, originadas do metabolismo das células e do ambiente ${ }^{6}$.

A cárie dentária é uma doença multifatorial decorrente da relação entre hospedeiro, alimentação, tempo e microrganismos. Quando presente, reponde pela formação do biofilme dental, que promove uma função primária no desenvolvimento da cárie. Em sua ausência, não há o surgimento da doença ${ }^{7}$. Assim, o controle do biofilme dental é uma condição considerável no aspecto da prevenção da cárie.

Segundo o Ministério da Saúde, mesmo com o aumento de ações de prevenções mais eficazes, a cárie dentária persiste como doença da cavidade oral mais comum entre adolescentes da faixa etária de 12 anos, afetando mais da metade dessa população ${ }^{8}$.

A maior parte dos produtos comercializados possui alto custo. Os fitoterápicos são uma excelente alternativa, pois apresentam como vantagens o baixo custo. Pode, ainda, ser utilizado em conjunto com outra droga, além de apresentar poucos efeitos colaterais quando se utilizado corretamente ${ }^{9}$.

Com a finalidade de realizar buscas e comprovar a eficácia das plantas medicinais sobre os microrganismos da placa bacteriana da cavidade oral, o propósito desse trabalho foi realizar uma breve revisão da literatura sobre as principais plantas medicinais que são utilizadas no combate ao biofilme bucal pelo mundo.

MATERIAL E MÉTODO

O presente estudo trata-se de uma análise de dados secundários, por meio de uma revisão de literatura do tipo narrativa, uma vez que compõe uma análise da literatura publicada sobre as plantas medicinais no combate ao biofilme bucal ${ }^{10}$. Para constituir as buscas foram utilizados os seguintes bancos de dados: BVS Brasil (Biblioteca Virtual em Saúde), Scielo (Scientific Eletronic Library Online), Pubmed (National Center for Biotechnology Information), LILACS (Literatura Latino-americana e do Caribe em Ciências da Saúde) e Medline.

Foram utilizados os descritores plantas medicinais, fitoterapia, biofilmes e placa dentária, além dos termos correspondestes em inglês e espanhol. Utilizaram-se como critérios de inclusão trabalhos publicados em português, inglês e espanhol no período de 2009 a 2019 no formato de artigo, tese e dissertação. Foram excluídos deste estudo os artigos publicados fora da cronologia e linguagem utilizados como critério inclusivo. Com base nas buscas foram avaliados os resumos das publicações, e os estudos que se adequaram aos critérios inclusivos foram lidos na íntegra, seu conteúdo analisado e discutido para a elaboração do presente estudo.

RESULTADOS E DISCUSSÃO

- Plantas da família Asteraceae

A família Asteraceae é formada por arbustos, subarbustos, ervas perenes, porém apresentam também árvores, lianas e ervas anuais, além de compreender por volta de 24000 espécies e 1700 gêneros, distribuídos em 43 tribos e três subfamílias ${ }^{11}$. Esta família é conhecida por suas propriedades terapêuticas como colestérico, antiinflamatório, antihemorrágico, antimicrobiano, diurético e analgésico ${ }^{12}$.

Uma espécie que já apresentou efeito no combate aos microorganismos das linhagens de Streptococcus mutans, Streptococcus sanguinis e Lactobacillus casei, que são os principais encarregados pela formação do biofilme dental, foi a Matricaria recutita Linn (Camomila) desenvolvendo uma potencial atividade antiaderência in vitro ${ }^{13}$.

Uma pesquisa realizada in vitro a partir do extrato de Matricaria recutita Linn, verificou que a camomila possui atividade antimicrobiana diante dos Streptococcus mutans, Streptococcus mitis, Streptococcus sanguinis, Streptococcus sobrinus e Lactobacillos casei, porém quando comparada a clorexidina a $0,12 \%$ este efeito não é muito eficaz ${ }^{14}$.

Testes clínicos randomizados em 59 indivíduos adultos que usaram bochechos a base de extratos de Aroeira (Schinus 
terebinthifolius) e Camomila (Matricaria recutita L.), mostraram resultados eficazes diante do controle da placa bacteriana como da gengivite periodontal crônica, resultados semelhantes a clorexidina a $0,12 \%$. Porém, o bochecho do extrato de Camomila apresentou melhores resultados quando comparados ao bochecho do extrato de Aroeira ${ }^{15}$.

Macêdo-Costa et al. ${ }^{16}$ avaliaram in vitro a comparação dos extratos de Matricaria recutita linn. e Myrciaria cauliflora Berg em relação a clorexidina a $0,12 \%$ sobre o biofilme dental. Todas as amostras das linhagens Streptococcus mutans, Streptococcus mitis, Streptococcus sanguinis e Lactobacillus casei, se mostraram sensíveis aos extratos abordados e comprovou a sua atividade antimicrobiana.

Um ensaio clínico randomizado controlado com 55 pacientes portadores de doença periodontal revelou que enxaguatórios de extrato de Matricaria recutita linn. reduziram o índice de placa e sangramento gengival tanto na periodontite crônica quanto na gengivite. Enquanto bochechos feitos com extrato da Punica granatum $l$. (Romã) apresentaram redução no índice de placa e sangramento na gengivite, porém não apresentou redução significativa no índice de placa na periodontite crônica quando comparado a clorexidina $0,12 \%{ }^{17}$.

- Plantas da família Anacardiaceae

A família Anacardiaceae apresenta poucos representantes em regiões temperadas, com maior ocorrência pantropical. Possui aproximadamente 600 espécies e 70 gêneros, onde muitas são utilizadas como antidiarreico, estomático, cicatrizante, pela presença de óleoresinas e taninos, como por exemplo o caju-docerrado (Anacardium humile A. St.-Hil.) ${ }^{18}$.

Uma espécie que já apresentou efeito no combate as bactérias formadoras do biofilme dentário foi a Schinus terebinthinfolius (Aroeira) e Solidago microglossa (Arnica) comparadas in vitro. Obteve-se como resultados atividades antimicrobianas e antiaderente frente aos $S$. mutans e L. casei. Uma informação bastante relevante, já que estas espécies são encontradas na maioria das pessoas e umas das principais responsáveis pela produção do biofilme dental ${ }^{19}$.

Existe um potencial efeito antimicrobiano (bactericida e bacteriostático) do extrato do caule do cajueiro (Anacardium occidentale Linn.) a partir de testes in vitro, sobre as linhagens de Streptococcus mutans, Streptococcus mitis, Streptococcus sanguis, Streptococcus sobrinus e Lactobacillus casei, sendo estes os mais importantes no desenvolvimento do biofilme dental ${ }^{20}$.

Após testes in vitro e in vivo com taninos extraídos brutos da casca do caule de Anacardium occidentale $L$. e de Anadenanthera macroscarpa (Benth.), demonstraram atividades bacteriostática diante das espécies Streptococcus mitis, Streptococcus mutans, Streptococcus oralis, Streptococcus salivarius, Streptococcus sanguinis, Streptococcus sanguinis, além de não serem tóxicos ao organismo ${ }^{21}$.

O extrato da Myracrodruon urundeuva (aroeira) in vitro apresenta melhor efeito antimicrobriano sobra os Streptococcus mutans, quando comparado ao extrato da Qualea grandiflora, porém ambos apresentam efeitos similares diante dos Lactobacilos casei ${ }^{22}$.

- Plantas da família Fabaceae

A família Fabaceae é a terceira maior botânica, está dividida em três subfamílias (Mimosoideae, Faboideae e caesalpinioideae), possui cerca de 17815 espécies e 619 gêneros ${ }^{23}$.

O extrato da Mimosa tenuiflora (Willd.) in vitro sobre as linhagens de Streptococcus mitis, Streptococcus mutans, Streptococcus sanguis, Streptococcus sobrinus e Lactobacillus casei apresentou significante atividade antibacteriana, além do efeito de inibição da produção de glucano representados pela aderência em vidro sobre todos estes microorganismos ${ }^{24}$.

- Plantas da família Leguminosae

A família Leguminosae possui concentração nas regiões subtropicais e tropicais, apresenta mais de 13000 espécies e cerca de 600 gêneros ${ }^{25}$.

O estudo de Jesus et al. ${ }^{26}$ que usou o extrato da casca de Pithecellobium cochliocarpum (gomez) sobre as linhagens de S. mutans, S. mitis, S. sanguis, S.oralis, $S$. salivares e L.casei, demonstrou ação antimicrobiana significativa e atividade inibitória mínima de aderência in vitro em biofilme bacteriano supragengival.

- Plantas da família Poaceae

A família Poaceae está classificada em 700 gêneros e apresenta aproximadamente 10000 espécies, espalhadas em praticamente todos os ambientes do mundo ${ }^{27}$.

A espécie Cymbopogon citratus, a partir do seu óleo essencial, apresentou um potencial antimicrobiano sobre os Streptococcus mutans, $S$. salivariu, $S$. oralis, principalmente sobre os Streptococcus mutans, que são bactérias formadoras do biofilme dentário ${ }^{28}$.

Após análise química in vitro do óleo essencial do Cymbopogon citratus, verificou-se que seu principal composto é o citral, que 
possui propriedades antimicrobianas e antibiofilme diante dos Streptococcus mutans. Porém, o óleo essencial não foi capaz de remover o bilfilme maduro ${ }^{29}$.

- Plantas da família Lythraceae

A família Lythraceae apresenta 31 gêneros, onde 18 gêneros no velho mundo e 13 gêneros no novo mundo. Possui cerca de 600 espécies, distribuídas por todos os continentes, com exceção da Antártida. Sua maior concentração está na América tropical, África, e pouca representatividade nas latitudes norte ${ }^{30}$.

Argenta et al. $^{31}$ realizaram um estudo dividido em duas etapas. Na primeira etapa in vitro, foram selecionadas 32 espécies de plantas medicinais e a partir de extratos etanólicos foram inoculados em meio de cultura com S. mutans. A planta que apresentou maior halo de inibição foi a Punica granatum com 18 $\mathrm{mm}$. Na segunda etapa in vivo, foram confeccionados dentifrícios que incluíam o extrato da romã na sua constituição em três concentrações diferentes, $1 \%, 3 \%$ e sem acréscimo. Após serem testados clinicamente em 30 voluntários pelo período de 8 dias, o dentifrício que apresentou a maior redução do biofilme dental foi a concentração de 3\%, porém não houve redução do grupo Streptococcus mutans.

- Plantas da família Lamiaceae

A família Lamiaceae abrange cerca de 3200 espécies e 200 gêneros distribuídos em todo o mundo, pertencente a ordem Tubiflorae Lamiales. Suas espécies são conhecidas por seu uso condimentar, e muitas já citadas por diversos autores por apresentarem atividade biológica $^{18}$.

Um estudo que aborda uma das espécies foi um ensaio clínico cruzado randomizado comparou 0 dentifrício convencional com outro a base do extrato alcoólico de Alecrim (Rosmarinus officinalis Linn.) em vinte e sete indivíduos sobre o biofilme dentel e o sangramento gengival. $O$ estudo demonstrou que o dentifrício do extrato de Alecrim apresentou resultados semelhantes quando comparado com o convencional em relação ao biofilme dentário. Porém, houve uma maior diminuição do sangramento gengival pelo uso do dentifrício a base de Alecrim ${ }^{32}$.

- Plantas da família Punicaceae

A família Punicaceae encontra-se presente em quase todo 0 mundo, suas espécies são conhecidas por propriedades antidiarreica, hemostática, antisséptico, antiviral e anti-helmíntica ${ }^{33}$.

Segundo Silva ${ }^{34}$ o enxaguatório a base

de Punica granatum linn. testado em 35 escolares através de um ensaio clínico duplocego, apresentou uma redução significativa no índice de placa e sangramento gengival semelhante ao da clorexidina $0,12 \%$. Demostrando sua eficácia e segurança no controle do biofilme dental e da inflamação gengival.

\section{- Plantas da família Piperaceae}

A família Piperaceae possui cerca de 8 gêneros que distribui aproximadamente 2515 espécies ${ }^{35}$. No continente americano várias espécies dessa família encontram-se distribuídas. No Brasil ocorre cerca de 500 espécies e cinco gêneros, encontrados principalmente na mata atlântica ${ }^{36}$.

Uma espécie que demonstrou ser capaz de inibir a aderência e reduzir a produção de ácidos provenientes da sacarose do Streptococcus mutans in vitro, além de não possuir citoxicidade para os seres humanos, foi o extrato da Piper aduncum. Podendo ser uma alternativa na prevenção do biofilme dental ${ }^{37}$.

- Plantas da família Bignoniaceae

A família Bigoniaceae é formada por cerca de 800 espécies distribuídas em 120 gêneros, está presente principalmente na África e América do sul. Suas espécies são lianas, arbustos, árvores, subarbustos, onde várias são conhecidas pelo uso na indústria ou por serem plantas ornamentais ${ }^{38}$.

O extrato da espécie Pyrostegia venusta in vitro demonstrou uma redução do $\mathrm{PH}$, capacidade de inibição de aderência, além da atividade antimicrobiana contra as espécies Streptococcus mutans, Streptococcus oralis, Streptococcus mitis e Candida albicans ${ }^{39}$.

- Plantas da família Arecaceae

A família Arecaceae está distribuída em 240 gêneros e aproximadamente 2522 espécies, é presente principalmente em zonas tropical e subtropical, sendo a única família da ordem Arecales Bromhead, além de possuir 5 subfamílias $^{40}$.

Um estudo demonstrou que o tacumã (Astrocarym vulgare) e a papunha (Bactris gasipae) apresentam um alto teor lipídico e de carotenos, substâncias alimentares que atuam inibindo as lesões cariosas. Após testes in sito com óleos extraídos dos frutos em 8 voluntários, a perda mineral e agregação bacteriana foram reduzidas, sendo que o óleo de papunha apresentou resultados mais imediatos, enquanto o óleo de tucumã apresentou resultados tardio. Por apresentar ação nas etapas iniciais de formação do biofilme, o óleo da papunha pode ser mais efetivo na prevenção da cárie dental ${ }^{41}$.

- Plantas da família Malvaceae

A família Malvaceae é constituída por 
4200 espécies e aproximadamente 250 gêneros, distribuídos principalmente em áreas temperadas. No Brasil estão presentes 375 espécies e 73 gêneros ${ }^{36}$.

Diante dos princípios ativos extraídos da folha da malva (Malva sylvestris), goiabeira (Psidium guajava Linn) e casca do caule da aroeira-do-sertão (Myracrodruon urundeuva All) algumas espécies de bactérias formadoras do biofilme dental mostraram-se sensíveis. O Lactobacillus casei demonstrou ser o mais sensível quando submetido ao extrato da aroeira-do-sertão. $O$ extrato da Psidium guajava Linn apresentou maior potencial antimicrobiano diante dos Streptococcus mutans. Os Streptococcus mutans e o Streptococcus sobrinus foram os mais sensíveis diante do extrato da malva ${ }^{42}$.

\section{- Plantas da família Xanthorrhoeaceae}

A família Xanthorrhoeaceae é encontrada em regiões tropicais em várias partes do mundo, é utilizada para fins medicinais e $\operatorname{cosméticos}^{43}$. Suas espécies são conhecidas por suas propriedades antiinflamatória, laxante, bactericida, cicatrizante, antifúngica e hidratante ${ }^{44}$.

Um estudo demonstrou que bochechos realizados com enxaguatórios contendo Aloe vera possuem resultados igualmente eficaz na redução do biofilme dental quando comparado a clorexidina $0,12 \%$. $O$ ensaio clínico randomizado foi realizado em 300 indivíduos, não apresentou diferença estatística significativa entre eles, além da babosa não apresentar nenhum efeito colateral ${ }^{45}$.

Um ensaio clínico randomizado com noventa pacientes testou a efetividade de creme dental contendo Aloe vera e outro contendo triclosan. O creme dental a base de babosa apresentou uma melhora no índice de placa, com resultados semelhantes ao apresentado com triclosan, demonstrando seu potencial antimicrobiano ${ }^{46}$.

\section{CONCLUSÃO}

Diante da revisão realizada pode-se concluir que o uso de plantas medicinais tem apresentado resultados bastante significativos na redução da formação do biofilme dental, seja por suas propriedades antimicrobianas ou pelo seu potencial antiaderente frente às bactérias formadoras do biofilme dental, segundo os dados levantados. Dentre as famílias mais utilizadas, destacaram-se as famílias Asteraceae e Anacardiaceae, sendo as que mais apresentaram estudos sobre esse tema.

REFERÊNCIAS

1. Assis C. Plantas medicinais na odontologia.
Rev bras odontol. 2009;6(1):72-5.

2. Sampaio LA, Oliveira DR, Kerntopf MR, Brito JFE, Menezes IRA. Percepção dos enfermeiros da Estratégia Saúde da Família sobre o uso da fitoterapia. REME. 2013;17(1):76-84.

3. Carvalho ACB, Silveira D. Drogas vegetais: uma antiga nova forma de utilização de plantas medicinais. Brasília Médica. 2010;48(2):219-37.

4. BRASIL Ministério da Saúde. Política Nacional de Práticas Integrativas e Complementares no SUS. Departamento de Atenção Básica. 2006.

5. BRASIL Ministério da Saúde. RENISUS Relação de Plantas Medicinais de Interesse ao SUS. 2009.

6. BRASIL Ministério da Saúde. Condições de saúde bucal da população brasileira. Projeto SB Brasil. 2010.

7. Marsh P, Martin MV. Microbiologia oral. 6. ed. São Paulo: Santos; 2005.

8. Buischi YP. Promoção de Saúde Bucal na Clínica Odontológica. São Paulo: Artes Médicas; 2000.

9. Jeon JG, Rosalen PL, Falsetta ML, Koo H. Natural products in caries research: current (Limited) knowledge, challenges and future perspective. Caries Res. 2011;45(3):243-63.

10. Galvão CM, Sawada NO, Trevizan MA. Revisão sistemática: recurso que proporciona a incorporação das evidências na prática da enfermagem. Rev Latino-am Enfermagem. 2004;12(3):549-56.

11. Mondin CA. A tribo Mutiseae Cass. (Asteraceae) sensu Cabrera, no Rio Grande do Sul e suas relações biogeográcas [dissertação]. Porto Alegre: Instituto de Biociências - UFRGS; 1996.

12. Jeon $\mathrm{HJ}$, Kang $\mathrm{HJ}$, Jung $\mathrm{HJ}$, Kang YS, Lim CJ, Kim YM et al. Anti-inflammatory activity of Taraxacum officinale. J Ethnopharmacol. 2008;115(1):82-8.

13. Albuquerque ACL, Pereira MSV, Pereira JV, Pereira LF, Silva DF, Macedo-costa MR et al. Efeito antiaderente do extrato da Matricaria recutita Linn. Sobre microorganismos do biofilme dental. Rev Odontol UNESP. 2010;39(1):21-5.

14. Albuquerque ACL, Pereira MSV, Pereira JV, Pereira LF, Macedo-costa MR, Higin JS. Efeito Antimicrobiano do extrato da Matricaria recutita Linn. (Camomila) sobre Microrganismos do Biofilme Dental. Pesq Bras Odontoped Clin Integr. 2010;10(3):451-55.

15. Lins R, Vasconcelos FH, Leite RB, Coelhosoares RS, Barbosa DN. Avaliação clínica de bochechos com extratos de Aroeira (Schinus terebinthifolius) e Camomila (Matricaria recutita L.) sobre a placa bacteriana e a gengivite. Rev Bras PI Med. 2013;15(1):112-120.

16. Macêdo-Costa MR, Albuquerque ACL, Pereira AV, Diniz DN, Pereira MSV, Pereira JV et al. Efeito antimicrobiano do extrato da Myrciaria 
cauliflora berg e Matricaria recutita linn. sobre microrganismos do biofilme dental. Rev Biol Farm. 2010;4(1):19-25.

17. Belém NM. Análise clínica e microbiológica do efeito de fitoterápicos na redução do biofilme dental e do sangramento gengival na doença periodontal [dissertação]. Campina Grande: Departamento de Odontologia - UEPB; 2011.

18. Lorenzi $\mathrm{H}$, Matos FJA. Plantas Medicinais no Brasil: nativas e exóticas. 2. ed. São Paulo: Nova Odessa; 2002.

19. Freires IA, Alves LA, Jovito VC, Almeida LFD, Castro RD, Padilha WWN. Atividades antibacteriana e antiaderente in vitro de tinturas de Schinus terebinthinfolius (Aroeira) e Solidago microglossa (Arnica) frente a bactérias formadoras do biofilme dentário. Odontol Clín-Cient. 2010;9(2):139-43.

20. Araújo CRF, Pereira JV, Pereira MSV, Alves PM, Higino JS, Martins AB. Concentração mínima bactericida do extrato do cajueiro sobre bactérias do biofilme dental. Pesq Bras Odontoped Clin Integr. 2009;9(2):187-91.

21. Araújo JSC. Investigação dos efeitos citotóxicos, genotóxico e o potencial antibacteriano associados ao biofilme dental dos taninos isolados de Anacarium occidentale Linn e Anadenanthera macroarpa Brenam [dissertação]. Campina Grande: Departamendo de Odontologia - UEPB; 2013.

22. Fabris RC. Concentração inibitória mínima e concentração bacteriana mínima de extratos hidroalcóolicos das folhas de Myracrodruon urundeuva all e Qualea grandiflora Mart. Sobre Streptococcus mutans e Lactobacillus casei [tese]. Bauru: Faculdade de Odontologia - USP; 2017.

23. Judd WS, Campbell CS, Kellogg EA, Stevens PF. Plant Systematics: A phylogenetic approach. 3. ed. Sunderland: Sinauer Associates; 1999.

24. Macêdo-costa MR, Pereira MS, Pereira LF, Pereira AV, Rodriques OG. Atividade Antimicrobiana e Antiaderente do Extrato da Mimosa tenuiflora (Willd). Poir. Sobre Microrganismos do Biofilme Dentário. Pesq Bras Odontoped Clin Integr. 2009;9(2):161-65.

25. Arruda MSP, Araújo MQ, Lobo LT, Souza AP, Alves SM, Santos LS et al. Potential allelochemicals isolated from Pueraria phaseoloides. Allelopathy J. 2005;15(2):211-20.

26. Jesus RPF, Costa MRM, Bastos IV, Couto GB, Pereira MSV, Souza IA. Ação antibacteriana e antiaderente de Pithecellobium Cochliocarpum (gomez) mac br sobre microrganismos orais. Odontol Clín-Cient. 2010;9(4):331-35.

27.GPWG (Grass Phylogeny Working Group). Phylogeny and subfamilial classification of the grasses (Poaceae). Ann Missouri Bot Gard. 2001;88(3):373-457.
28. Perazzo MF, Neta MCC, Cavalcanti YW, Xavier AFC, Cavalcanti AL. Efeito antimicrobiano do Óleo Essencial do Cymbopogon citratus Sobre Bactérias Formadoras do Biofilme Dentário. R Bras ci Saúde. 2012;16(4):553-58.

29. Silva NB. Efeito do óleo essencial de Cymbopogon citratus (DC) stapf. no controle químico do biofilme dentário [dissertação]. Campina Grande: Departamento de Odontologia - UEPB; 2016.

30.Graham SA. Phylogenetic Relationships and Biogeography of the Endemic Caribbean Genera Crenea, Ginoria and Haitia (Lythraceae). J Sci. 2002;38(1):195-204

31. Argenta JA, Pasqual M, Pereira CV, Dias DR, Barbosa RA, Pereira LJ. Efeito do extrato de romã (Punica granatum) sobre bactérias cariogênicas: estudo in vitro e in vivo. Arq Odontol. 2012;48(4):218-26.

32. Tenório LA. A avaliação clínica da atividade do dentifrício à base do extrato de Rosmarinus officinalis linn. (Alecrim) sobre o biofilme dentalum estudo preliminar [dissertação]. Recife: Departamento de Odontologia - UFPE; 2014.

33. Menezes SMS, Pinto DM, Cordeiro LN. Atividades biológicas in vitro e in vivo de Punica granatum L. (romã). Rev Bras Med. 2008;65(11):388-91.

34. Silva FRS. Avaliação clínica da efetividade de um enxaguatório (Punica granatum linn.) sobre - controle de biofilme dentário inflamação gengival em escolares [monografia]. Campina Grande: Departamento de Odontologia - UEPB; 2014.

35. Machado NS. Estudo da anatomia foliar de espécies do gênero Piper L. (Piperaceae) no estado do Rio de Janeiro [tese]. Rio de Janeiro: Departamento de Ciências Biológicas - UFRJ; 2007.

36. Souza VC, Lorenzi H. Botânica sistemática: guia ilustrado para identificação das famílias de Angiospermas da flora brasileira, baseado em APG II. São Paulo: Nova Odessa; 2005.

37. Magalhães CF. Efeito de extratos e frações de Piper aduncum sobre o crescimento e metabolismo dos Streptococcus mutans e Streptococcus sanguis [dissertação]. Governador Valadares: Departamento de Ciências Biológicas - UNIVALE; 2010.

38. Parker T. Trees of Guatemala. 2008;7(1):86-90.

39. Sousa MB. Extratos de Pyrostegia venusta: Caracterização física-química, capacidade imunomoduladora e prevenção da formação do biofilme dental [dissertação]. Belém: Instituto de Ciências da Saúde - UFPA; 2013.

40. Dransfield JUH, Asmussen CB, Baker WJ, Haley MM, Lewis CE. Genera Palmarum: The Evolution and Classification of Palms. 2nd ed. Reino Unido: Kew Publishing; 2008. 
41.Emmi DT. Influência dos óleos do tucumã (Astrocaryum vulgare) e da papunha (Bactris gasipae) na composição do biofilme dental e dinâmica do processo de cárie em esmalte: um estudo in situ [dissertação]. São Paulo: Faculdade de Odontologia - USP; 2013.

42. Alves PM, Queiroz LM, Pereira JV, Pereira MS. Atividade antimicobiana, antiaderente e antifúngica in vitro de plantas medicinais brasileiras sobre micorganismos do biofilme dental e cepas do gênero Candida. Rev Soc Bras Med Trop. 2009;42(2):222-24.

43. Parente LML, Carneiro LM, Tresvenzol LMF, Gardin NEl. Aloe vera: características botânicas, fitoquímicas e terapêuticas. Arte Méd Ampl. 2013;33(4):160-64.

44. Fenner R, Betti AH, Mentz LA, Rates SMK. Plantas utilizadas na medicina popular brasileira com potencial antifúngico. Braz J Pharm Sci. 2006;42(3):369-74.

45. Kumar GR, Devanand G, Johnn BD, Ankit Y, Khursheed $O$, Sumit M. Preliminary antiplaque efficacy of Aloe vera mouthwash on 4 day plaque re-growth model randomized control trial. Ethiop J Health Sci. 2014;24(2):139-44.

46. Pradeep AR, AgarwaL E, Naik SB. Clinical and Microbiologic Effects of Commercially Available Dentifrice Containing Aloe Vera: A Randomized Controlled Clinical Trial. J Periodontol. 2012; 83(6):797-804.

\section{CONFLITO DE INTERESSES}

Os autores declaram não haver conflitos de interesse

\section{AUTOR PARA CORRESPONDÊNCIA}

\author{
Abrahão Alves de Oliveira Filho \\ Unidade Acadêmica de Ciências Biológicas do Centro \\ de Saúde e Tecnologia Rural da Universidade Federal \\ de Campina Grande \\ 58428-830 Campina Grande - PB, Brasil \\ E-mail: abrahao.farm@gmail.com
}

Submetido em 24/05/2019

Aceito em 23/10/2020 